\title{
The Impact of Intraoperative Blood Loss on the Long-term Prognosis after Curative Resection for Borrmann Type IV Gastric Cancer: A Retrospective Multicenter Study
}

\author{
HIROSHI TAMAGAWA ${ }^{1,2^{*}}$, TORU AOYAMA ${ }^{1 *}$, KAZUKI KANO ${ }^{1}$, MASAKATSU NUMATA ${ }^{1}$, YOSUKE ATSUMI ${ }^{1}$, \\ KENTARO HARA ${ }^{1}$, KEISUKE KAZAMA ${ }^{1}$, KEISUKE KOUMORI ${ }^{1}$, MASAAKI MURAKAWA ${ }^{1}$, \\ ITARU HASHIMOTO $^{1}$, YUKIO MAEZAWA $^{1}$, TAKANOBU YAMADA ${ }^{1,2}$, NORIO YUKAWA $^{1}$, \\ TAKAKI YOSHIKAWA ${ }^{1,3}$, MUNETAKA MASUDA ${ }^{1}$, TAKASHI OSHIMA $^{1,2}$ and YASUSHI RINO ${ }^{1}$ \\ ${ }^{1}$ Department of Surgery, Yokohama City University, Yokohama, Japan; \\ ${ }^{2}$ Department of Gastrointestinal Surgery, Kanagawa Cancer Center, Yokohama, Japan; \\ ${ }^{3}$ Department of Gastric Surgery, National Cancer Center Hospital, Tokyo, Japan
}

\begin{abstract}
Background/Aim: To evaluate the outcomes of curative resection for Borrmann type IV gastric cancer through an analysis of the clinical, surgical and pathological data and through identifying which of these prognostic factors are associated with survival. Patients and Methods: We retrospectively analyzed 2798 patients who had undergone excision of the primary lesion and 122 patients with type IV gastric cancer undergoing curative resection (RO or 1) at Yokohama City University Hospital and Kanagawa Cancer Center between November 1995 and May 2016. Results: Borrmann type IV gastric cancer had more advanced and unfavorable clinicopathological factors compared to other types. The 5-year overall survival rate was $28 \%$, and the median survival was 21.8 months. The overall survival rate was influenced by the depth of invasion, lymph node metastasis, peritoneal lavage cytology $(C Y)$, stage and intraoperative blood loss. Of these, independent prognostic factors were intraoperative blood loss ( $<400 \mathrm{vs} . \geq 400 \mathrm{ml}$, risk ratio $1.64 ; p=0.045)$ and $C Y$ (0 vs. 1, risk ratio 2.25; $p=0.004)$. Conclusion: The control of intraoperative bleeding had a positive impact on the
\end{abstract}

*These Authors contributed equally to this study.

Correspondence to: Hiroshi Tamagawa, Department of Surgery, Yokohama City University, 3-9 Fukuura, Kanazawa-ku, Yokohama 236-0004, Japan. Tel: +81-457872800, Fax: 0457870226, e-mail: rinta77-nosuke@amber.plala.or.jp; Toru Aoyama, Department of Surgery, Yokohama City University, 3-9 Fukuura, Kanazawa-ku, Yokohama 236-0004, Japan. Tel: +81 457872800, Fax: 0457870226, e-mail: t-aoyama@lilac.plala.or.jp

Key Words: Intraoperative blood loss, overall survival, prognosticator, gastric cancer. survival of patients receiving curative resection for Borrmann type IV gastric cancer.

Gastric cancer is the fifth-most common malignancy and was the third leading cause of cancer-related death in 2018 (1). Radical gastrectomy with regional lymph node dissection is indispensable for curing localized gastric cancer (2). However, recurrence may occur in $20 \%-60 \%$ patients even if complete resection is achieved $(3,4)$.

The prognosis of advanced gastric cancer depends on a variety of different factors, including the tumor size, depth of invasion, nodal metastases and pathological type $(5,6)$. The classification of advanced gastric cancer according to Borrmann's criteria is presently accepted worldwide by endoscopists and surgeons. Among advanced gastric cancer types, Borrmann types I and II have relatively good outcomes, whereas the survival outcomes of Borrmann type IV cancer, known as linitis plastica, are extremely poor (1, 7-9). Although several neoadjuvant and postoperative adjuvant chemotherapies have been established, their effect on the long-term prognosis of Borrmann type IV gastric cancer is still insufficient (10). This is due in part to patients who undergo postoperative chemotherapy often having an inadequate nutritional intake, resulting in postoperative chemotherapy of insufficient dose intensity (11). The prognosis of patients with Borrmann type IV gastric cancer is poor, with a 5-year overall survival rate after gastrectomy ranging from $10.5 \%$ to $27.6 \%$ (12).

A number of potential prognostic factors have recently been reported, such as perioperative blood transfusion and intraoperative blood loss. Burrow et al. (13) first reported the risk connected with perioperative blood transfusions in colorectal cancer patients in 1982. For gastric cancer, Kaneda et al. (14) reported that blood transfusion was 


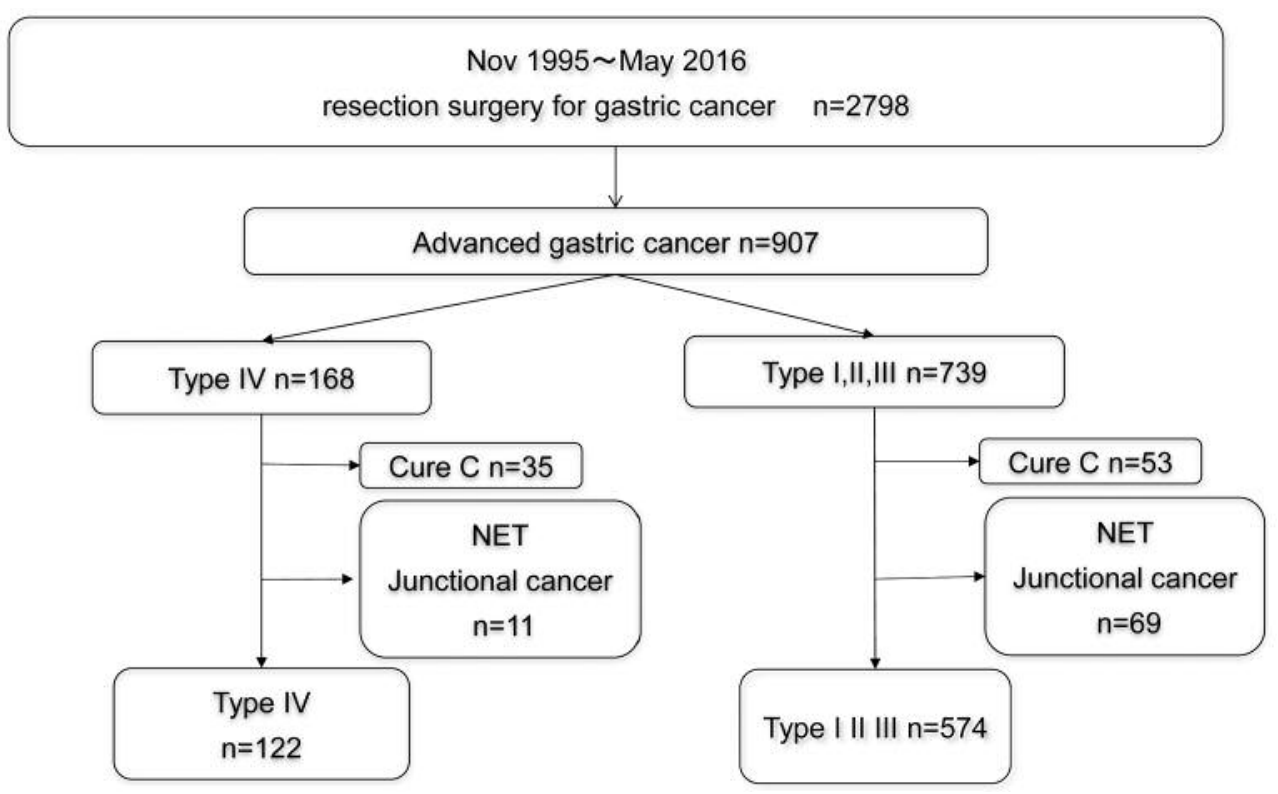

Figure 1. Consort diagram.

Table I. Comparison of patient background factors between the Borrmann type IV gastric cancer and other Borrmann types.

\begin{tabular}{|c|c|c|c|c|}
\hline Variables & All patients $(n=696)$ & Borrmann I, II, III (n=574) & Borrmann IV $(n=122)$ & $p$-Value \\
\hline Age (years), median (range) & $67(29-86)$ & $67(29-86)$ & $63(31-80)$ & $<0.001$ \\
\hline Gender & & & & $<0.001$ \\
\hline Female & $221(31.8 \%)$ & $162(28.2 \%)$ & $59(48.4 \%)$ & \\
\hline Male & $475(68.2 \%)$ & $412(71.8 \%)$ & $63(51.6 \%)$ & \\
\hline Body mass index, median (range) & $21.9(13.6-32.4)$ & $22.1(13.6-32.4)$ & $21.4(13.7-30.1)$ & 0.010 \\
\hline ASA-PS & & & & 0.079 \\
\hline 1 & $212(30.9 \%)$ & $165(29.2 \%)$ & $47(39.5 \%)$ & \\
\hline $2-3$ & $473(69.1 \%)$ & $401(70.8 \%)$ & $72(60.5 \%)$ & \\
\hline Surgical method & & & & $<0.001$ \\
\hline Total gastrectomy & $358(51.4 \%)$ & $252(43.9 \%)$ & $106(86.9 \%)$ & \\
\hline Gastrectomy & $338(48.6 \%)$ & $322(56.1 \%)$ & $16(13.1 \%)$ & \\
\hline Tumor size, median (range) & $56.0(4-230)$ & & & $<0.001$ \\
\hline Nodal dissection & & & & 0.066 \\
\hline $\mathrm{D} 1+$ & $98(14.1 \%)$ & $73(12.7 \%)$ & $25(20.5 \%)$ & \\
\hline $\mathrm{D} 2$ & $598(85.9 \%)$ & $501(87.3 \%)$ & $97(79.5 \%)$ & \\
\hline Operation time (min), median (range) & $199(80-668)$ & $209(80-668)$ & $210(101-523)$ & 0.919 \\
\hline Blood loss (ml), median (range) & $252(5-3,780)$ & $337(5-3,780)$ & $394(5-1,920)$ & 0.100 \\
\hline Histological type & & & & $<0.001$ \\
\hline Well to moderate & $244(38.9 \%)$ & $241(47.0 \%)$ & $3(2.6 \%)$ & \\
\hline Poorly, signet, mucinous & $384(61.1 \%)$ & $272(53.0 \%)$ & $112(97.4 \%)$ & \\
\hline Pathological $\mathrm{T}$ factor & & & & $<0.001$ \\
\hline pT1-3 & $304(47.3 \%)$ & $284(49.5 \%)$ & $20(16.4 \%)$ & \\
\hline pT4 & $392(56.3 \%)$ & $290(150.5 \%)$ & $102(83.6 \%)$ & \\
\hline Pathological $\mathrm{N}$ factor & & & & 0.513 \\
\hline pNO & $217(67.9 \%)$ & $182(31.7 \%)$ & $35(68.3 \%)$ & \\
\hline pN1-3 & $479(32.1 \%)$ & $392(28.7 \%)$ & $87(71.3 \%)$ & \\
\hline Adjuvant chemohetrapy & & & & $<0.001$ \\
\hline Yes & $1,823(80.9 \%)$ & $286(49.8 \%)$ & $38(31.1 \%)$ & \\
\hline No & $431(19.1 \%)$ & $288(50.2 \%)$ & $84(68.9 \%)$ & \\
\hline
\end{tabular}

ASA-PS: American Society of Anesthesiologists physical status. 




Figure 2. Relapse-free survival with Borrmann type I-III and type IV gastric cancer.

correlated with a poor outcome. Similarly, excessive intraoperative blood loss increases the risk of postoperative recurrence and of a poor prognosis in patients with several cancers. However, there are still few articles concerning the correlation between intraoperative blood loss and long-term outcome of patients with gastric cancer.

In this study, we performed a large-scale, retrospective, multi-center cohort analysis of stage II or III Borrmann type IV gastric cancer with curative gastrectomy to compare the outcomes with those from other types of cancer and clarify the significance of clinicopathological features, such as intraoperative blood loss, on survival.

\section{Patients and Methods}

Patients. The patients were retrospectively selected from among the medical records of consecutive patients who underwent gastrectomy with nodal dissection for gastric cancer at Yokohama City University and Kanagawa Cancer Center from November 1995 to May 2016. Patients with the following criteria were included: 1) histologically proven gastric adenocarcinoma, 2) D2 or D1+ gastrectomy with curative lymph node dissection as the first treatment and 3) achieved complete (R0 or R1) resection.

In principle, D1+ gastrectomy was selected for clinical T1 cancer, while D2 gastrectomy was selected for clinical T2-T4 disease according to the Japanese gastric cancer treatment guidelines, ver. 3 . The resected specimens were histopathologically examined and staged according to the Japanese classification of gastric carcinoma: 3rd English edition. The location of lesions was determined by the macroscopic appearance of the surgical specimen and from a postoperative histological examination after the stomach was divided into three parts (upper, middle and lower).

All patients who underwent radical gastrectomy from November 1995 to May 2016 were followed up at an outpatient clinic and received surgery alone. After August 2006, pathological stage II and III patients received S-1 adjuvant chemotherapy based on the ACTS-GC trial, which became the standard treatment for advanced gastric cancer.

Patients were followed up at outpatient clinics. The dates and causes of death were collected from the follow-up data based on hematological tests and physical examinations performed at least every three months for the first three years after surgery and then every six months until five years after surgery. The serum CEA and CA19-9 levels were checked at least every three months for five years. Patients underwent a computed tomography (CT) examination every six months during the first three years after surgery and then every year until five years after surgery. Postoperative complications of grade 2-5 according to the Clavien-Dindo classification that occurred during hospitalization and/or within 30 days after surgery were retrospectively determined from the patient's records. Grade 1 complications were not evaluated in order to exclude the possibility of a description bias in the patient's records. 


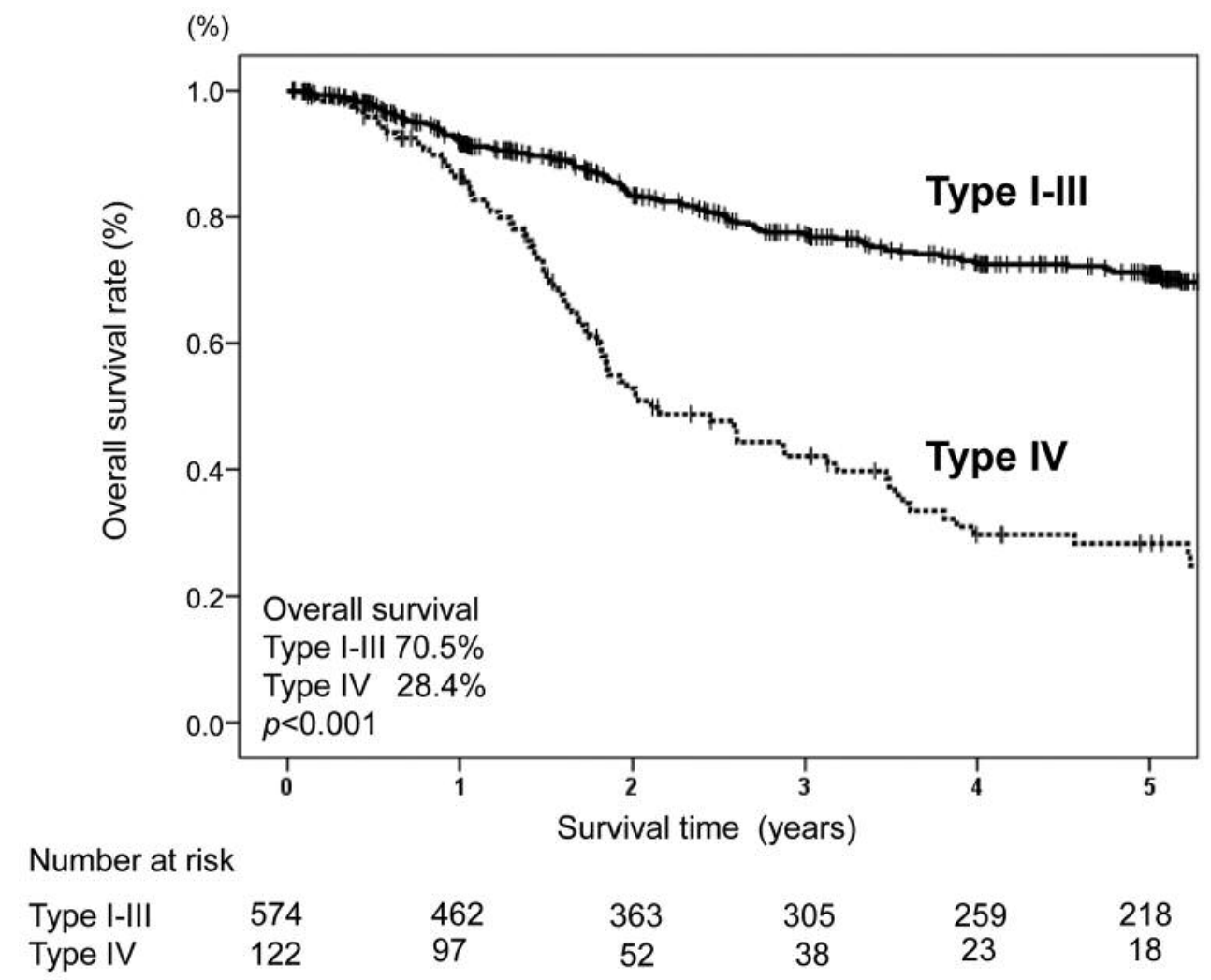

Figure 3. Overall survival with Borrmann type I-III and type IV gastric cancer.

Statistical analyses. The significance of the correlation between the Borrmann Type I-III group, Borrmann Type IV group and clinicopathological parameters was determined using Fisher's exact test or the $\chi^{2}$ test and the Mann-Whitney $U$-test for continuous variables. The overall survival (OS) was defined as the period between surgery and death. Recurrence-free survival (RFS) was defined as the period between surgery and recurrence or death, whichever came first. The data of the patients who did not experience an event were censored on the date of the final observation. OS and RFS curves were calculated by the Kaplan-Meier method and compared by the log-rank test. OS was evaluated by univariate and multivariate analyses using Cox's proportional hazard model. To select a model, we used backward elimination in the multivariate analysis. Patients with missing covariate values were excluded. Standard clinical thresholds were used, dividing the continuous variables into no more than two categories. $p$-Values of $<0.05$ were considered to indicate statistical significance. The survival data were obtained from hospital records or from the city registry system. The SPSS software program (ver. 23.0; IBM Corp., Armonk, NY, USA) was used to perform all the statistical analyses.

This study was approved by the Institutional Review Board (IRB) of the Yokohama City University (IRB Number: B160707003) and Kanagawa Cancer Center (2016.epidemiologic study-22).

\section{Results}

Clinicopathological features. A flow diagram of the selection process is shown in Figure 1. We evaluated 696 patients in the present study, including 122 patients with stage II or III Borrmann type IV gastric cancer who underwent curative resection and 574 patients with other types of gastric cancer.

Table I summarizes the clinicopathological data of the patients with Borrmann type IV gastric cancer and other types of cancer. There were significant differences in the distribution of age, gender, body mass index, surgical method, tumor size, histological types, pathological $\mathrm{T}$ factor and adjuvant chemotherapy between the two groups. The Borrmann type IV cases tended to be younger, more often female and had a lower body mass index than the other cases. Regarding the treatment method, total gastrectomy was performed frequently, but there were a few cases in which adjuvant chemotherapy was given for the Borrmann type IV group. The size of the tumor was larger, depth of cancer invasion deeper and lesions more poorly differentiated in the Borrmann type IV group than in the other types.

Long-term outcomes. During a median follow-up of 36 months, the 5-years RFS rate in patients with Borrmann type IV and other types of cancer was $25.3 \%$ and $63.8 \%$ (Figure 2), respectively, and the 5-years OS rate was 
Table II. Univariate and multivariate Cox proportional hazards analyses of the clinicopathological factors associated with overall survival in Type IV gastric cancer.

\begin{tabular}{|c|c|c|c|c|c|c|c|}
\hline \multirow[t]{2}{*}{ Characteristics } & \multirow[t]{2}{*}{ Number } & \multicolumn{3}{|c|}{ Univariate } & \multicolumn{3}{|c|}{ Multivariate } \\
\hline & & HR & $95 \% \mathrm{CI}$ & $p$-Value & HR & $95 \% \mathrm{CI}$ & $p$-Value \\
\hline Age (years) & & & & 0.206 & & & \\
\hline$<60$ & 45 & 1.00 & & & & & \\
\hline$\geq 60$ & 77 & 0.74 & $0.48-1.17$ & & & & \\
\hline Gender & & & & 0.187 & & & \\
\hline Female & 59 & 1.00 & & & & & \\
\hline Male & 63 & 1.35 & $0.87-2.09$ & & & & \\
\hline ASA-PS & & & & 0.781 & & & \\
\hline 1 & 47 & 1.00 & & & & & \\
\hline $2-3$ & 72 & 0.78 & $0.49-1.24$ & & & & \\
\hline Histological Type & & & & 0.321 & & & \\
\hline Well to moderate & 3 & 1.00 & & & & & \\
\hline Poorly, signet, mucinous & 112 & 2.72 & $0.38-19.6$ & & & & \\
\hline Locations of lesion & & & & 0.027 & & & 0.138 \\
\hline$<1 / 3$ & 24 & 1.00 & & & 1.00 & & \\
\hline$>2 / 3$ or whole stomach & 97 & 2.20 & $1.10-4.42$ & & 1.774 & $0.83-3.78$ & \\
\hline Abdominal cytology & & & & $<0.001$ & & & 0.004 \\
\hline Negative & 87 & 1.00 & & & 1.00 & & \\
\hline Positive & 29 & 2.70 & $1.68-4.35$ & & 2.25 & $1.30-3.89$ & \\
\hline Lymph node dissection & & & & 0.369 & & & \\
\hline $\mathrm{D} 1+$ & 25 & 1.00 & & & & & \\
\hline D2 & 97 & 0.78 & $0.46-1.34$ & & & & \\
\hline Blood loss & & & & 0.009 & & & 0.045 \\
\hline$<400$ & 80 & 1.00 & & & 1.00 & & \\
\hline$\geq 400$ & 42 & 1.84 & $1.16-2.90$ & & 1.64 & $1.01-2.67$ & \\
\hline Pathological $\mathrm{T}$ factor & & & & 0.036 & & & 0.447 \\
\hline pT1-3 & 20 & 1.00 & & & 1.00 & & \\
\hline pT4 & 102 & 2.19 & $1.05-4.56$ & & 1.38 & $0.60-3.16$ & \\
\hline Pathological $\mathrm{N}$ factor & & & & 0.045 & & & 0.512 \\
\hline pNO & 35 & 1.00 & & & 1.00 & & \\
\hline pN1-3 & 87 & 1.68 & $1.01-2.79$ & & 1.21 & $0.69-2.14$ & \\
\hline Adjuvant chemotherapy & & & & 0.571 & & & \\
\hline Yes & 73 & 1.00 & & & & & \\
\hline No & 49 & 1.14 & $0.73-1.77$ & & & & \\
\hline
\end{tabular}

ASA-PS: American Society of Anesthesiologists physical status.

$28.4 \%$ and $70.5 \%$ (Figure 3$)$, respectively $(p<0.001)$. In patients with Borrmann type IV gastric cancer, the median survival was 21 months. The 5-year OS rate was influenced by the tumor size, depth of invasion, lymph node metastasis, locations of lesion, CY and intraoperative blood loss (Table II). A significant survival benefit was noted for an intraoperative blood loss of $<400 \mathrm{ml}$, with a 5 -year RFS rate of $2.1 \%$ compared to patients who lost $\geq 400 \mathrm{ml}(0 \%, p<0.001)$ (Figure 4$)$. The 5 -year OS was $34.9 \%$ for $<400 \mathrm{ml}$ and $16.3 \%$ for $\geq 400 \mathrm{ml}$ of blood loss $(p<0.001)$ (Figure 5). Six factors that were significant in the univariate analysis were included in the multivariate analysis, which indicated that survival was independently influenced by intraoperative blood loss and CY positivity (Table II).

\section{Discussion}

Since the Borrmann classification system was developed in 1926, it has been generally accepted and widely adopted. However, despite advances in diagnostic methods, Borrmann type IV gastric cancer is still detected at an advanced stage, and survival rates for these patients remain poor $(15,16)$. Some retrospective studies reported that the 5-year OS of patients with Borrmann type IV gastric cancer was only $10.5 \%$ to $16.7 \%(12,17,18)$. In our study, the 5-year RFS rate in patients with Borrmann type IV disease was $25.3 \%$, while the 5-year OS rate was $28.4 \%$. In previous studies, Borrmann type IV gastric cancer was reported to have characteristic features, such as a young female prominence, advanced stage of detection, high frequency of peritoneal 
(\%)



Figure 4. Relapse-free survival in the low and high intraoperative blood loss groups.

recurrence and low rate of curative resection compared to other types $(12,19-21)$. In this study, the age at diagnosis tended to be younger, female gender more frequent and detection made at a more advanced stage in cases of Borrmann type IV gastric cancer than in other cases.

The present study examined the clinicopathological parameters in Borrmann type IV gastric cancer and identified six significant risk factors affecting the long-term survival, and CY positivity and intraoperative blood loss were independent risk factors according to the multivariate analysis. In Borrmann type IV gastric cancer, previous studies have reported an early diagnosis and prompt treatment as crucial for improving prognosis. Zhu et al. (12) reported that the independent prognostic factors were lymph node metastasis and radical resection, and Yook et al. (22) found in their univariate analysis that the prognostic factors affecting the survival rate following curative resection were the location, occupied area and depth of the primary tumor along with the presence of lymph node metastasis and also the tumor stage. The early detection and radical resection have been reported to be essential for improving the prognosis of patients with Borrmann type IV gastric cancer.

Intraoperative blood loss has been reported to be associated with the prognosis of digestive carcinoma (23, 24). In hepatocellular carcinomas, Katz et al. (23) reported that increased intraoperative blood loss during hepatic resection is an independent prognostic factor for tumor recurrence and death. In pancreatic cancers, Nagai et al. (24) reported that intraoperative blood loss was a prognostic determinant of survival after surgery for pancreatic cancer and that operative blood loss could be used to stratify risk for pancreatic cancer mortality. There have also been reports that suggest that minimizing intraoperative blood loss is very important for ensuring a good outcome, although it was not found to be an independent prognostic factor for cancer patients $(25,26)$. Several papers describe the correlation of intraoperative blood loss and prognosis in cases of gastric cancer. Yue-Xiang Liang et al. (27) reported that intraoperative blood loss was an independent prognostic factor for gastric cancer after curative resection. Reducing intraoperative blood loss can improve the long-term outcome of gastric cancer patients following curative gastrectomy. Ito et al. (28) also reported that intraoperative blood loss adversely influenced the long-term outcomes of patients with stage II/III gastric cancer. However, no reports have described the correlation of intraoperative blood loss with the prognosis of Borrmann type IV gastric cancer. In the present study, the survival was independently influenced by intraoperative blood loss and the presence of $\mathrm{CY}$ in patients with Borrmann type IV gastric cancer. 


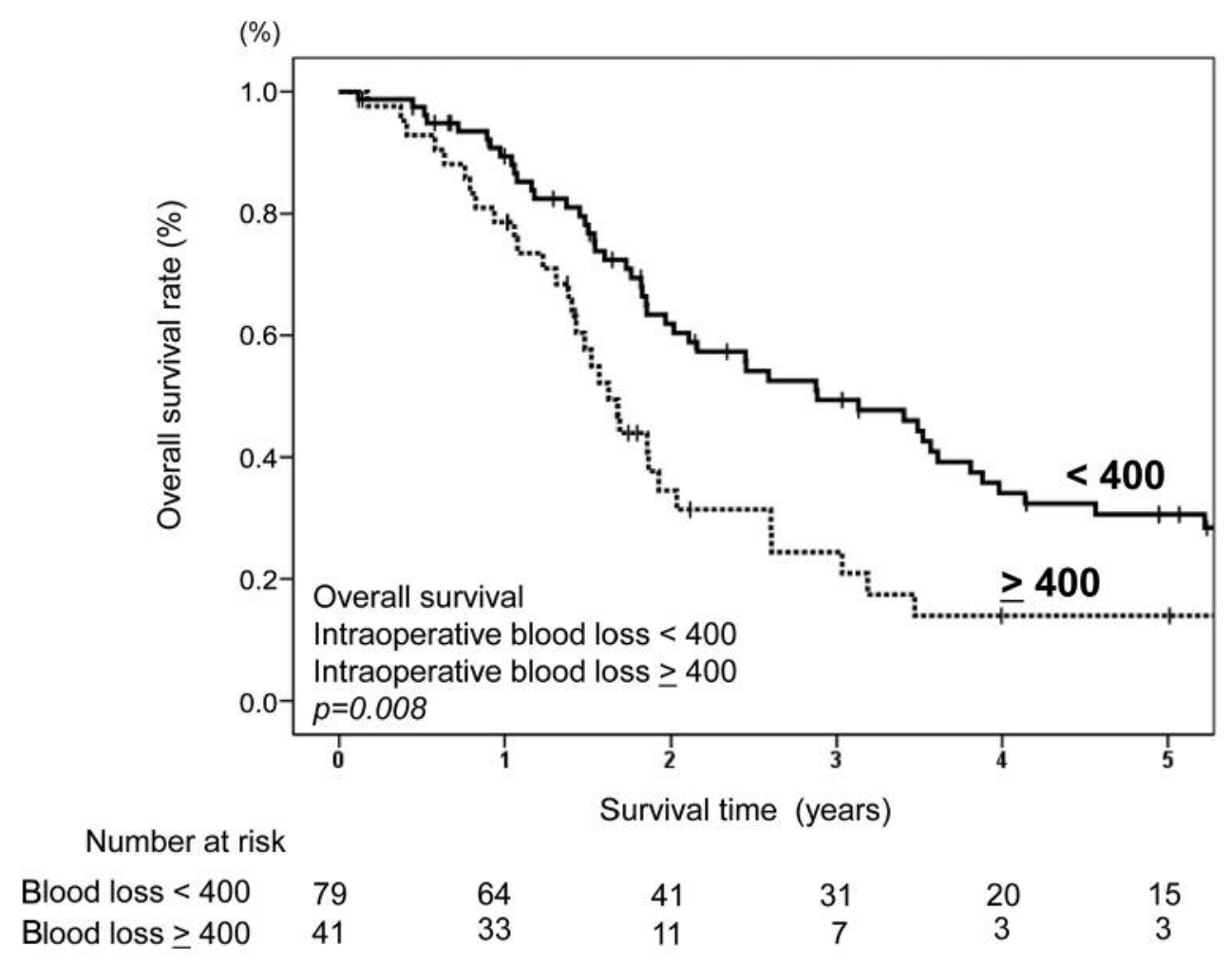

Figure 5. Overall survival in the low and high intraoperative blood loss groups.

Several limitations associated with the present study warrant mention. First, this was a retrospective study with a relatively small sample size, so a large-scale prospective validation study is needed. Second, the present study did not use a uniform cut-off value for intraoperative blood loss. Therefore, different statistical methods may obtain different values. Third, the use of different postoperative therapies might have introduced a confounding result.

In conclusion, this study of a multicenter database showed that intraoperative blood loss was an independent prognostic factor for Borrmann type IV gastric cancer after curative resection. Reducing the intraoperative blood loss may improve the prognosis of Borrmann type IV gastric cancer.

\section{Conflicts of Interest}

The Authors declare that they have no competing interests related to this study.

\section{Authors' Contributions}

HT and TA made substantial contributions to conception and design. HT, TA, KK (Kazuki Kano), MN, YA, KH, KK2 (Keisuke Kazama), KK3 (Keisuke Koumori), MM1 (Masaaki Murakawa), IH, YM, TY1 (Takanobu Yamada), NY, TY2 (Takaki Yoshikawa), MM (Munetaka Masuda), TO, and YR made substantial contributions to acquisition of data, or analysis and interpretation of data. TA, KK, YA, HT, AT, KK2 and YR have been involved in drafting the manuscript or revising it critically for important intellectual content. TA, YM, KK3, KH, MM, MN, TO, and MM have given final approval of the version to be published. Each Author participated sufficiently in the work to take public responsibility for appropriate portions of the content, and agreed to be accountable for all aspects of the work in ensuring that questions related to the accuracy or integrity of any part of the work are appropriately investigated and resolved. All Authors read and approved the final manuscript.

\section{References}

1 An JY, Kang TH, Choi MG, Noh JH, Sohn TS and Kim S: Borrmann Type IV: An Independent prognostic factor for survival in gastric cancer. J. Gastrointest Surg 12: 1364-1369, 2008. PMID: 18516653. DOI: 10.1007/s11605-008-0516-9

2 Dicken BJ, Bigam DL, Cass C, Mackey JR, Joy AA and Hamilton SM: Gastric adenocarcinoma: review and considerations for future directions. Ann Surg 241: 27-39, 2005. PMID: 15621988. DOI: 10.1097/01.sla.0000149300.28588.23

3 Aoyama $\mathrm{T}$ and Yoshikawa $\mathrm{T}$ : Adjuvant therapy for locally advanced gastric cancer. Surg Today 47: 1295-1302, 2017. PMID: 28251375. DOI: 10.1007/s00595-017-1493-y

4 Yoshikawa T, Rino Y, Yukawa N, Oshima T, Tsuburaya A and Masuda M: Neoadjuvant chemotherapy for gastric cancer in Japan: a standing position by comparing with adjuvant 
chemotherapy. Surg Today 44: 11-21, 2014. PMID: 23508452. DOI: $10.1007 / \mathrm{s} 00595-013-0529-1$

5 Marrelli D, Morgagni P, de Manzoni G, Coniglio A, Marchet A, Saragoni L, Tiberio G, Roviello F and Italian Research Group for Gastric Cancer (IRGGC): Prognostic value of the 7th AJCC/UICC TNM classification of noncardia gastriccancer: analysis of a large series from specialized Western centers. Ann Surg 255: 486-491, 2012. PMID: 22167003. DOI: 10.1097/SLA.0b013e3182389b1a

6 Hayashi T, Yoshikawa T, Bonam K, Sue-Ling HM, Taguri M, Morita S, Tsuburaya A, Hayden JD and Grabsch HI: The superiority of the seventh edition of the TNM classification depends on the overall survival of the patient cohort: comparative analysis of the sixth and seventh TNM editions in patients with gastric cancer from Japan and the United Kingdom. Cancer 119: 1330-1337, 2013. PMID: 23280435. DOI: 10.1002/cncr.27928

7 Kinoshita T, Sasako M, Sano T, Katai H, Furukawa H, Tsuburaya A, Miyashiro I, Kaji M and Ninomiya M: Phase II trial of S-1 for neoadjuvant chemotherapy againstscirrhous gastric cancer (JCOG 0002). Gastric Cancer 12: 37-42, 2009. PMID: 19390930. DOI: 10.1007/s10120-008-0496-1

8 Yamashita K, Sakuramoto S, Katada N, Kikuchi S and Watanabe M: Simple prognostic indicators using macroscopic features and age in advanced gastric cancer. Hepatogastroenterology 61(130): 512517, 2014. PMID: 19390930. DOI: 10.1007/s10120-008-0496-1

9 Yamashita K, Hosoda K, Katada N, Moriya H, Mieno H, Higuchi K, Sasaki T, Katada C, Sakuramoto S, Tanabe S, Koizumi W, Kikuchi S and Watanabe M: Survival outcome of Borrmann type IV gastric cancer potentially improved by multimodality treatment. Anticancer Res 35: 897-906, 2015. PMID: 25667472.

10 Sun XC, Lin J and Ju AH: Treatment of Borrmann type IV gastric cancer with a neoadjuvant chemotherapy combination of docetaxel, cisplatin and 5-fluorouracil/leucovorin. J Int Med Res 39: 20962102, 2011. PMID: 22289524. DOI: 10.1177/147323001103900605

11 Aoyama T, Yoshikawa T, Shirai J, Hayashi T, Yamada T, Tsuchida K, Hasegawa S, Cho H, Yukawa N, Oshima T, Rino Y, Masuda $\mathrm{M}$ and Tsuburaya A: Body weight loss after surgery is an independent risk factor for continuation of S-1 adjuvant chemotherapy for gastric cancer. Ann Surg Oncol 20: 2000-2006, 2013. PMID: 23242818. DOI: 10.1245/s10434-012-2776-6

12 Zhu YL, Yang L, Sui ZQ, Liu L and Du JF: Clinicopathological features and prognosis of Borrmann type IV gastric cancer. J BUON 21: 1471-1475, 2016. PMID: 28039710.

13 Burrows L and Tartter P: Effect of blood transfusions on colonic malignancy recurrent rate. Lancet 2: 662, 1982. PMID: 6125797. DOI: $10.1016 / \mathrm{s} 0140-6736(82) 92764-7$

14 Kaneda M, Horimi T, Ninomiya M, Nagae S, Mukai K, Takeda I, Shimoyama H, Chohno S, Okabayashi T, Kagawa S and Orita $\mathrm{K}$ : Adverse affect of blood transfusions on survival of patients with gastric cancer. Transfusion 27: 375-377, 1987. PMID: 3629666. DOI: 10.1046/j.1537-2995.1987.27587320526.x

15 Kim DY, Kim HR, Kim YJ and Kim S: Clinicopathological features of patients with Borrmann type IV gastric carcinoma. ANZ J Surg 72: 739-742, 2002. PMID: 12534387. DOI: 10.1046/j.1445-2197.2002.02523.x

16 An JY, Kang TH, Choi MG, Noh JH, Sohn TS and Kim S: Borrmann type IV: an independent prognostic factor for survival in gastric cancer. J Gastrointest Surg 12(8): 1364-1369, 2008. PMID: 18516653. DOI: 10.1007/s11605-008-0516-9

17 Otsuji E, Yamaguchi T, Sawai K, Sakakura C, Okamoto K and Takahashi T: Regional lymph node metastasis as a predictor of peritoneal carcinomatosis in patients with Borrmann type IV gastric carcinoma. Am J Gastroenterol 94: 434-437, 1999. PMID: 10022642. DOI: 10.1111/j.1572-0241.1999.873_b.x

18 Chen CY, Wu CW, Lo SS, Hsieh MC, Lui WY and Shen KH: Peritoneal carcinomatosis and lymph node metastasis are prognostic indicators in patients with Borrmann type IV gastric carcinoma. Hepatogastroenterology 49: 874-877, 2002. PMID: 12064011.

19 An JY, Kang TH, Choi MG, Noh JH, Sohn TS and Kim S: Borrmann type IV: an independent prognostic factor for survival in gastric cancer. J Gastrointest Surg 12: 1364-1369, 2008. PMID: 18516653. DOI: 10.1007/s11605-008-0516-9

20 Kodera Y, Yamamura Y, Ito S, Kanemitsu Y, Shimizu Y, Hirai T, Yasui $\mathrm{K}$ and Kato T: Is Borrmann type IV gastric carcinoma a surgical disease? An old problem revisited with reference to the result of peritoneal washing cytology. J Surg Oncol 78: 175-181, 2001. PMID: 11745801. DOI: 10.1002/jso.1144

21 Otsuji E, Kuriu Y, Okamoto K, Ochiai T, Ichikawa D, Hagiwara A and Yamagishi $\mathrm{H}$ : Outcome of surgical treatment for patients with scirrhous carcinoma of the stomach. Am J Surg 188: 327-332, 2004. PMID: 15450843. DOI: 10.1016/j.amjsurg.2004.06.010

22 Yook JH, Oh ST and Kim BS: Clinicopathological analysis of Borrmann type IV gastric cancer. Cancer Res Treat 37: 87-91, 2005. PMID: 19956485. DOI: 10.4143/crt.2005.37.2.87

23 Katz SC, Shia J, Liau KH, Gonen M, Ruo L, Jarnagin WR, Fong Y, D'Angelica MI, Blumgart LH and Dematteo RP: Operative blood loss independently predicts recurrence and survival after resection of hepatocellular carcinoma. Ann Surg 249: 617-623, 2009. PMID: 19300227. DOI: 10.1097/SLA.0b013e31819ed22f

24 Nagai S, Fujii T, Kodera Y, Kanda M, Sahin TT, Kanzaki A, Yamada S, Sugimoto H, Nomoto S, Takeda S, Morita S and Nakao A: Impact of operative blood loss on survival in invasive ductal adenocarcinoma of the pancreas. Pancreas 40: 3-9, 2011. PMID: 20881897. DOI: 10.1097/MPA.0b013e3181f7147a

25 Zhao B, Huang X, Lu H, Zhang J, Luo R, Xu H and Huang B: Intraoperative blood loss does not independently affect the survival outcome of gastric cancer patients who underwent curative resection. Clin Transl Oncol 21: 1197-1206, 2019. PMID: 30689183. DOI: 10.1007/s12094-019-02046-6

26 Arima K, Hashimoto D, Okabe H, Inoue R, Kaida T, Higashi T, Taki K, Nitta H, Hayashi H, Chikamoto A, Beppu T and Baba $\mathrm{H}$ : Intraoperative blood loss is not a predictor of prognosis for pancreatic cancer. Surg Today 46: 792-797, 2016. PMID: 26302976. DOI: $10.1007 / \mathrm{s} 00595-015-1238-8$

27 Liang YX, Guo HH, Deng JY, Wang BG, Ding XW, Wang XN, Zhang $\mathrm{L}$ and Liang $\mathrm{H}$ : Impact of intraoperative blood loss on survival after curative resection for gastric cancer. World J Gastroenterol 19: 5542-5550, 2013. PMID: 24023499. DOI: 10.3748/wjg.v19.i33.5542

28 Ito Y, Kanda M, Ito S, Mochizuki Y, Teramoto H, Ishigure K, Murai T, Asada T, Ishiyama A, Matsushita H, Tanaka C, Kobayashi D, Fujiwara M, Murotani $\mathrm{K}$ and Kodera $\mathrm{Y}$ : Intraoperative blood loss is associated with shortened postoperative survival of patients with stage II/III gastric cancer: Analysis of a Multi-institutional Dataset. World J Surg 43: 870877, 2019. PMID: 30377722. DOI: 10.1007/s00268-018-4834-0

Received November 29, 2019

Revised December 4, 2019

Accepted December 6, 2019 